\title{
Atypical Brain Activation of Reading Processes in Children with Developmental Dyslexia.
}

Citation for published version (APA):

Backes, W. H., Vuurman, E. F. P. M., Wennekes, R., Spronk, P., Wuisman, M., van Engelshoven, J. M. A., \& Jolles, J. (2002). Atypical Brain Activation of Reading Processes in Children with Developmental Dyslexia. Journal of Child Neurology, 17(12), 867-871. https://doi.org/10.1177/08830738020170121601

Document status and date:

Published: 01/01/2002

DOI:

10.1177/08830738020170121601

Document Version:

Publisher's PDF, also known as Version of record

\section{Please check the document version of this publication:}

- A submitted manuscript is the version of the article upon submission and before peer-review. There can be important differences between the submitted version and the official published version of record.

People interested in the research are advised to contact the author for the final version of the publication, or visit the DOI to the publisher's website.

- The final author version and the galley proof are versions of the publication after peer review.

- The final published version features the final layout of the paper including the volume, issue and page numbers.

Link to publication

\footnotetext{
General rights rights.

- You may freely distribute the URL identifying the publication in the public portal. please follow below link for the End User Agreement:

www.umlib.nl/taverne-license

Take down policy

If you believe that this document breaches copyright please contact us at:

repository@maastrichtuniversity.nl

providing details and we will investigate your claim.
}

Copyright and moral rights for the publications made accessible in the public portal are retained by the authors and/or other copyright owners and it is a condition of accessing publications that users recognise and abide by the legal requirements associated with these

- Users may download and print one copy of any publication from the public portal for the purpose of private study or research.

- You may not further distribute the material or use it for any profit-making activity or commercial gain

If the publication is distributed under the terms of Article $25 \mathrm{fa}$ of the Dutch Copyright Act, indicated by the "Taverne" license above, 


\title{
Atypical Brain Activation of Reading Processes in Children With Developmental Dyslexia
}

\author{
Walter Backes, PhD; EricVuurman, MSc; Rianne Wennekes, MD; Patricia Spronk, MSc; Mea Wuisman, BSc; \\ J os van Engelshoven, PhD; J elle J olles, PhD
}

\begin{abstract}
Brain activation differences of reading-related processes between dyslexic and normal reading children were localized with functional magnetic resonance imaging (MRI). The children performed tasks that varied in visuospatial, orthographic, phonologic, and semantic processing demands. Enhanced activation of the left extrastriate cortex was found during all tasks in the dyslexic group. During orthographic processing, dyslexic children predominantly showed activation in the right prefrontal cortex, as also occurred during the visuo-spatial task. Normal readers also showed activation in the left prefrontal cortex. Dyslexic readers showed less activation of both the temporal and the prefrontal cortex during phonologic processing. The results suggest that dyslexic readers fail to use brain areas that are normally specialized in language processing, but rather use areas that underlie visuospatial processing. (J Child Neurol 2002;17:867-871).
\end{abstract}

Developmental dyslexia is characterized by impaired reading abilities in children who have the intelligence, motivation, and other abilities necessary for adequate reading and in whom reading difficulties are not attributable to acquired brain injury or sociocultural factors. ${ }^{1-3} \mathrm{~A}$ core problem lies in the lack or incomplete development of the automatization processes that are necessary for word identification or word spelling. ${ }^{4}$ Dyslexic readers suffer from impairment in the ability to deal in an abstract way with sound elements of language, have a decreased "phonological awareness," and therefore find it difficult to transfer printed language into sound structures. 6,7

Proposed theories on dyslexia point at disrupted neuropsychologic mechanisms that are related to atypical Ianguage lateralization, visuoperceptive disorders, or deficits in phonologic processing in the temporal cortex. ${ }^{8,9} \mathrm{Evi}-$ dence is also accumulating that nonlinguistic symptoms such as a lack of concentration, disorganization, forgetful-

Received J uly 7, 2002. Received revised August 20, 2002. Accepted for publication August 20, 2002.

From the Departments of Radiology (Drs Backes and van Engelshoven) and Neurology (Dr Wennekes), Maastricht University Hospital, and the Brain and Behavior Institute (Mr Vuurman, Ms Spronk, Ms Wuisman, and Dr J olles), Maastricht University, Maastricht, The Netherlands.

Address correspondence to Dr Walter Backes, Department of Radiology, University Hospital of Maastricht, P. Debyelaan 25, 6229 HX Maastricht. Tel: ++31-43-3876948; fax: ++31-43-3876911; e-mail: wbac@rdia.azm.nl. ness, and executive dysfunction can be present in dyslexics. ${ }^{3}$ These findings are of interest in view of recent neuroimaging data in adult dyslexics that show differential involvement of frontal and temporal structures in dyslexia versus controls. ${ }^{10}$ Unfortunately, there is a lack of functional neuroimaging data on dyslexic children, and the two studies that have been performed in children differ from one another with regard to the population studied. Georgiewa et al compared dyslexics at the age of 9 to 17 years, of whom 50\% were female. ${ }^{11}$ Temple et al, on the other hand, studied younger children, aged around 11 years, with approximately $80 \%$ males. ${ }^{12}$ The composition of the group of subjects to be studied is important in view of the functional disruption in the organization of the brain for reading in dyslexia and the developmental nature of the condition. ${ }^{10}$ Moreover, there is ample evidence that the brains of boys and girls mature differently, ${ }^{13,14} \mathrm{w}$ hereas dyslexia is far more prevalent in boys than in girls. ${ }^{15}$ Finally, boys and girls differ in visuospatial processing and involvement of the right hemisphere. ${ }^{16}$ This suggests that it is important to control for the factors age and sex when planning a neuroimaging study of dyslexic children.

The present functional magnetic resonance imaging (MRI) study was designed specifically for the investigation of brain activation differences in four component processes of reading in a homogeneous group of children. Age and sex were controlled to keep within-group differences in brain activation and information processing strategies as low as possible. The 
study was performed with dyslexic boys aged 11 to 12 years. A comparison was made of perceptual (visuospatial), orthographic, phonologic, and semantic processes in a hierarchically structured task design. It was expected that valid inferences could best be investigated in such a homogeneous group and that follow-up research could be programmed to evaluate the possible generalizability of the findings

\section{METHODS}

\section{Subjects}

Eight boys were recruited from a dyslexia outpatient clinic, and eight boys with no history of developmental dyslexia or language disorders acted as controls. None of the children had any history of neurologic or psychiatric disease. All dyslexic children were outpatients from the Maastricht Dyslexia Centre, which is a multidisciplinary facility related to the Maastricht University Hospital. They were subjected to a comprehensive diagnostic intervention consisting of a linguistic and an orthodidactic part ( 2.5 hours) and a neurocognitive/neuropsychologic part ( 2.5 hours). The diagnostic battery consisted of tests that evaluated reading abilities, other verbal abilities, auditive and visual abilities, auditive and visual analysis and synthesis, auditive and visual discrimination, auditive and visual memory, writing, attentional functions, planning, and problem solving, as well as strategies and possible compensation mechanisms. The diagnosis was made by a multidisciplinary team of a neuro/psycholinguist, child neuropsychologist, and child psychologist. All children had been taught to read according to a standardized educational reading method. ${ }^{17}$ The selection criteria ensured that the intelligence of all children was normal (IQ > 85). All subjects were right-handed ${ }^{18}$ and had Dutch as their first language. Before imaging, the children had to perform the 1-minute reading test, ${ }^{19}$ during which they had to read aloud as many words as possible. The mean of the number of words correctly read was 80 (SD 9) for the normal group and 24 (SD 11) for the dyslexic group. The mean age was 11.6 (SD 0.7) and 11.5 (SD 1.2) for the normal and dyslexic groups, respectively. Informed consent was obtained from all parents and children. The medical ethics committee of the hospital approved the study.

\section{Tasks and Procedures}

The subjects performed four-choice reaction time tasks that were hierarchically structured with respect to the increasing demands on verbal coding and reading capabilities. These tasks were adapted from a design previously used in adult dyslexics. ${ }^{10,20} \mathrm{~A}$ response with a button held in the right hand was required if the stimulus items matched. The match-to-mismatch ratio of all trials was 0.5 . The first task, a visual line orientation task (eg, // $\Lambda$ - $M$ ), required visuospatial processing, without demand on language. The second task, string comparison, added orthographic processing by comparing two consonant strings. The third task, nonword rhyming, additionally required phonologic processing because two monosyllable pseudow ords had to be judged as to whether they rhymed. The fourth task, semantic category judgment, added semantic processing and required a decision as to whether both monosyllable words represented animals. In the latter task, the subjects were familiar with all of the words presented. To balance the visual input, each of the items consisted of four characters.

The entire procedure lasted between 2 and 3 hours and was conducted over 2 days for each subject. During the functional MRI runs, the tasks were presented in epochs of 32 seconds and alternated by epochs of 32 seconds during which a fixation cross had to be viewed. New stimulus pairs were presented every $5 \mathrm{sec}-$ onds. The subjects observed the visual stimuli from a mirror fixed above the head as computer-controlled (E-Prime, Psychology Software Tools, Inc., 1999) projections. Reaction times of the subjects were measured with a fiber-optic response system.

\section{Functional MRI and Data Analysis}

Images were acquired on a 1.5 Tesla MRI system (Philips ACS-NT, Philips Medical Systems) with a receiver head coil. The functional scan acquisitions consisted of a single-shot multislice $\mathrm{T}_{2}{ }^{*}$-weighted echo planar imaging sequence, which was sensitive to the blood oxygen level-dependent effect. The acquisition parameters were TR $5600 \mathrm{msec}$, TE $40 \mathrm{msec}$, flip angle 90 degrees, matrix dimension $64 \times 64,40$ contiguous slices, voxel dimensions $3.5 \times 3.5 \times 3.5$ $\mathrm{mm}^{3}$, and 85 volumes. Further details on the acquisition and data processing have been previously described..$^{21}$

The statistical significance of the activation was inferred from the resulting statistical parametric maps SPM $\{Z\}$ (Statistical Parametric Mapping, SPM99, Wellcome Department of Cognitive Neurology, London, UK) of the general linear model. ${ }^{22}$ The SPMs were first calculated for each task and each subject to reveal the parameter estimates of the activations by contrasting the reading condition with the baseline condition. Then the significance of the activated cortical areas was inferred from a random effect analysis for both groups separately. ${ }^{23}$ Second, for each task, the resulting parameter estimates of each reading condition were contrasted between the two groups in a random effect analysis to explicitly localize the differences in activation between dyslexic and normal readers. Local areas with a sufficiently large number of connected and significantly activated voxels (ie, clusters) were considered to be significant $(\mathrm{Pc}<.05)$ by cluster-based statistics and reported as stereotaxic coordinates. ${ }^{24}$

\section{RE SULTS}

\section{Behavioral Performance}

There were no differences between dyslexic and normal subjects for the line orientation and the string comparison task. For the nonword rhyming and the semantic category task, however, the dyslexics performed significantly $(P<.001)$ more slowly and less accurately than normal readers. Mean reaction time for the rhyme task was 3809 msec (SD 612) for the dyslexic group and $2441 \mathrm{msec}$ (SD 207) for the normal readers. In the semantic judgment task, the mean reaction time was 2847 (SD 499) msec for the dyslexic group and 1934 msec (SD 917) for the controls.

\section{Brain Activation}

For the line orientation task (Table 1), the parietal cortex showed more activation in the normal readers, whereas 
Table 1. Activations for the Four Reading Tasks for Normal (N12) and Dyslexic (D12) Readers Together With the Differences Between the Groups

\begin{tabular}{|c|c|c|c|c|c|c|}
\hline & \multirow[b]{2}{*}{ Cortex } & \multirow[b]{2}{*}{$B A$} & \multicolumn{2}{|c|}{ Normals } & \multicolumn{2}{|c|}{ Dyslexics } \\
\hline & & & $(x, y, z)$ & Maximum Z & $(x, y, z)$ & Maximum Z \\
\hline \multicolumn{7}{|l|}{ Line orientation } \\
\hline & Inferior/middle & 44,45 & $(-46,4,36)$ & 3.7 & & \\
\hline & Prefrontal & & $(50,8,32)$ & $4.0 * *$ & $(54,8,16)$ & $3.6^{* *}$ \\
\hline & Cingulate & 32 & & & $(4,10,56)$ & $3.9 * *$ \\
\hline & Posterior parietal & 7,40 & $(-22,-72,56)$ & $4.6^{* *}$ & $(-34,-54,66)$ & $3.7 * *$ \\
\hline & & & $(30,-72,48)$ & $4.6 * *$ & $(20,-78,52)$ & $4.0 * *$ \\
\hline & Occipital & $17,18,19$ & $(-26,-92,16)$ & $5.2 * *$ & $(-4,-80,6)$ & $4.6^{* *}$ \\
\hline & & & $(28,-94,20)$ & $4.8^{* *}$ & $(48,-60,-8)$ & $4.2 * *$ \\
\hline \multicolumn{7}{|l|}{ String comparison } \\
\hline & Inferior prefrontal & 44,45 & $(-54,16,4)$ & $4.6^{* *}$ & & \\
\hline & & & $(54,18,-12)$ & 3.1 & $(52,18,-12)$ & $4.3 * *$ \\
\hline & Cingulate & 32 & $(0,0,58)$ & $3.6 * *$ & $(0,8,58)$ & $4.2 * *$ \\
\hline & Posterior parietal & 7,40 & $(-24,-72,50)$ & $3.4 *$ & & \\
\hline & & & $(40,-66,52)$ & $4.5^{* *}$ & & \\
\hline & Occipital & $17,18,19$ & $(-26,-94,2)$ & $4.7 * *$ & $(-22,-92,2)$ & $4.8 * *$ \\
\hline \multirow{2}{*}{\multicolumn{7}{|c|}{ Nonword rhyming }} \\
\hline & & & & & & \\
\hline & Inferior/middle & 44,45 & $(-52,38,-6)$ & $4.5^{* *}$ & & \\
\hline & Prefrontal & & $(-54,12,34)$ & $3.4 *$ & $(-34,20,-2)$ & 3.7 \\
\hline & & & $(42,42,36)$ & $3.5^{*}$ & & $(\mathrm{Pc}=.07)$ \\
\hline & Cingulate & 32 & $(10,16,50)$ & $4.1^{*}$ & & \\
\hline & Superior/ & & & & & \\
\hline & middle temporal & $38,21,22$ & $(-38,18,-24)$ & $3.5^{* *}$ & & \\
\hline & & & $(-56,-40,-4)$ & $4.3^{*}$ & & \\
\hline & & & $(58,-34,0)$ & 3.0 & & \\
\hline & Posterior parietal & 7,40 & $(-36,-64,54)$ & $3.9 *$ & $(-28,-62,48)$ & $3.3^{*}$ \\
\hline & & & $(26,-68,50)$ & $3.9 *$ & & \\
\hline & Occipital & $17,18,19$ & $(-34,70,-2)$ & $5.0 * *$ & $(-30,-50,-20)$ & $5.0 * *$ \\
\hline & & & $(16,-90,-8)$ & $5.1^{* *}$ & $(28,-90,-8)$ & $4.7 * *$ \\
\hline \multicolumn{7}{|l|}{ Semantic judgment } \\
\hline & Inferior/ & & & & & \\
\hline & middle frontal & $44,45,6,8,9$ & $(-42,18,-8)$ & $4.3^{* *}$ & $(-34,24,0)$ & $3.3^{* *}$ \\
\hline & & & $(-38,34,12)$ & $4.2^{* *}$ & & \\
\hline & & & $(-46,4,30)$ & $4.1 * *$ & $(34,22,-12)$ & $3.9 *$ \\
\hline & & & $(36,8,30)$ & $3.8 * *$ & & \\
\hline & Cingulate & 32 & $(-2,10,50)$ & $4.5^{*}$ & $(6,18,42)$ & $4.0 * *$ \\
\hline & Superior temporal & $21,22,32$ & & & $(-34,22,-16)$ & $4.6^{* *}$ \\
\hline & Posterior parietal & 7,40 & & & $(-26,-62,42)$ & $3.1 *$ \\
\hline & & & $(32,-68,56)$ & 3.3 & $(34,-56,40)$ & $3.3^{*}$ \\
\hline & Occipital & $17,18,19$ & $(-38,-94,-4)$ & $4.1 * *$ & $(-26,-56,-14)$ & $4.2^{* *}$ \\
\hline & & & $(20,-96,4)$ & $4.7 * *$ & $(14,-50,-14)$ & $4.3^{* *}$ \\
\hline
\end{tabular}

Listed are the cortical areas, Brodmann areas (BA), Talairach coordinates, and maximum $\mathrm{Z}$ value in a significant cluster (Pc $\leq .05 ; * \mathrm{Pc} \leq .01 ; * * \mathrm{Pc} \leq .001)$.

the left lateral extrastriate cortex was more strongly activated in the dyslexic readers (Figure $1 \mathrm{~A}$ ).

The string comparison task induced bilateral activation in the inferior frontal cortex in the normal readers (Figure 1B). The dyslexic readers, however, only showed activation on the right side (Figure 1C). Moreover, the left inferior prefrontal cortex (Broca's area) was more strongly activated in the normal readers. The left lateral extrastriate cortex showed more activation in the dyslexic readers.

For the nonword rhyming task, the activation (F igure 1D and $\mathrm{IE}$ ) in the left inferior prefrontal region was stronger in the normal readers. The cingulate gyrus was observed to be activated only in the normal group. The dyslexic readers showed no activation of the temporal cortex, whereas the normal readers showed bilateral activation in the superior temporal cortex. The right posterior parietal activation was higher in normal readers, whereas the dyslexic readers, again, showed stronger activation in the left extrastriate cortex.
For the semantic category task, the inferior prefrontal cortex was activated for the normal readers in the left but not in the right hemisphere. The dyslexic readers, on the contrary, showed significant bilateral inferior prefrontal activity, which was particularly stronger in the left hemisphere. For this task, the bilateral extrastriate cortex showed stronger activation in the dyslexic readers.

\section{DISCUSSION}

The most striking result of this study is the interhemispheric activation difference between dyslexic and normal readers in the inferior prefrontal cortex for the string comparison task, which ought to require orthographic language processing. It is of interest that despite nearly equal task performances, dyslexic readers exhibit more right than left inferior prefrontal brain activity. The residual left inferior prefrontal brain activation of the dyslexic children was 


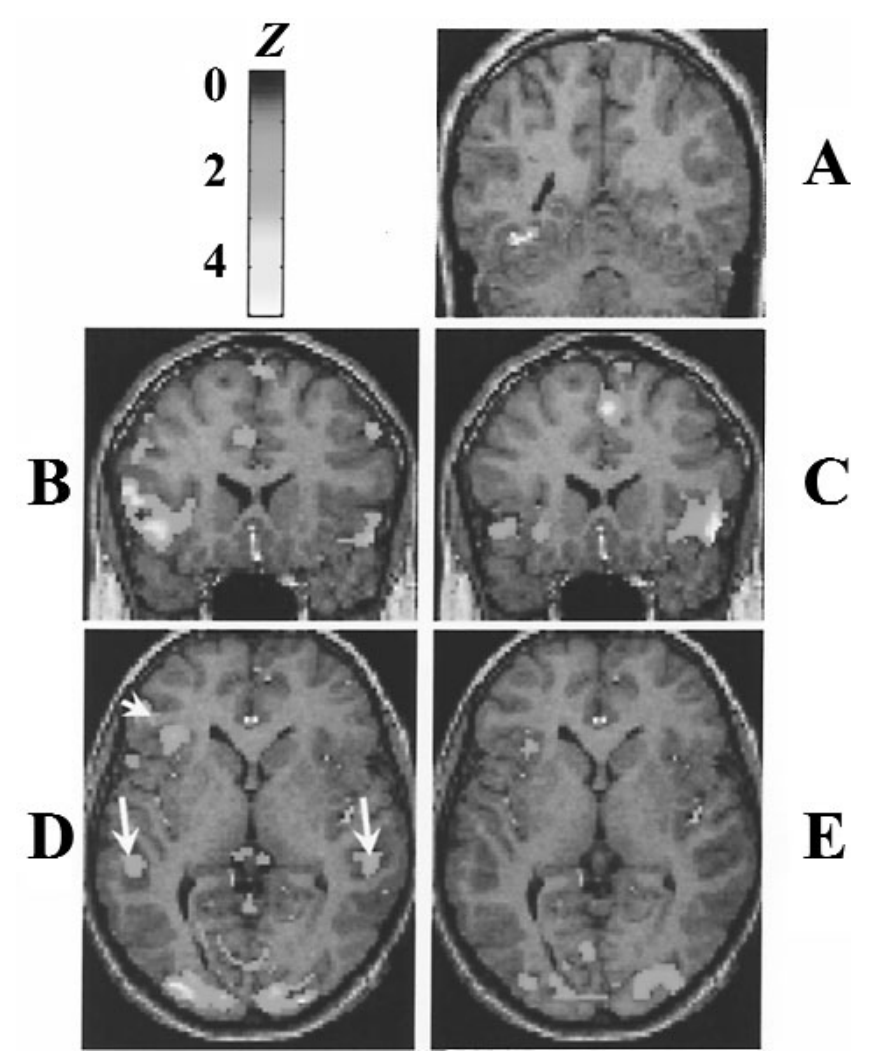

Figure 1. Depicted is the overactivation (D12 $>$ N12) in the left lateral extrastriate cortex of the dyslexic readers relative to normal readers at $y=<199>58 \mathrm{~cm}(A)$. The activation for the normal (B) and dyslexic readers $(C)$ for the string comparison task is shown in the inferior prefrontal cortex at $y=18 \mathrm{~cm}$. The activation pattern in the inferior prefrontal cortex (arrowhead) and the temporal cortex (arrows) are depicted for the rhyme task in the normal (D) and dyslexic readers (E) at $\mathrm{Z}=0 \mathrm{~cm}$. The color bar indicates the superimposed color-coded $Z$ values $(P<.01)$ representing group averages.

lower than for normal readers. As the left inferior prefrontal cortex (Broca's area) is known to be crucial for language processes, the results may indicate that dyslexic children use another processing strategy and other brain circuits to execute the orthographic reading task at a level of performance comparable to the normal readers. The results suggest that dyslexic children make use of a visuospatial feature processing strategy and activate the right prefrontal cortex when matching the letter sequences in the same way as occurs during the line orientation task for both dyslexic and normal readers.

The notion of enhanced visual spatial feature processing could also explain the systematically stronger activation of the left lateral extrastriate cortex in dyslexic children. The left part of the visual cortex is specialized in processing high spatial frequency information, ${ }^{25}$ which is necessary for complex feature integration during letter or symbol perception. Activation differences in the left lateral extrastriate cortex for dyslexic children have recently been claimed in a study contrasting a line orientation with a letter matching task. ${ }^{12}$ The authors found that the left extrastriate cortex showed a higher activation difference between the letter and line task for normal compared with dyslexic readers. Consequently, they reasoned that the orthographic processes in normal readers activate the left extrastriate cortex more strongly than in dyslexic children. This study now brings about an alternative explanation. The difference is purely owing to enhanced visuospatial feature processing and not to decreased orthographic processing activation. Previous conclusions are possibly based on the potential pitfalls of the subtraction design that was used.

The few existing and independent imaging studies on dyslexia have not all shown decreased inferior prefrontal brain activity in comparison with normal readers. Using functional MRI in dyslexic children versus normals, Georgiewa et al did show stronger activation in the inferior frontal cortex in normals relative to dyslexics for tasks demanding specifically assembled phonologic coding processes. ${ }^{11}$ Their findings agree with our results in the nonword rhyming task. A similar underactivation of the left prefrontal area was found in adult dyslexics by Paulesu et al in a rhyming task and by Brunswick et al in a positron emission tomographic (PET) study with other reading tasks. ${ }^{26,27}$ On the other hand, Shaywitz et al demonstrated by using functional MRI that adult dyslexic subjects exhibited decreased activation in the inferior frontal gyrus for a single lettercase matching task but increased activity for both a singleletter rhyming and a nonword rhyming task..$^{10}$ It is conceivable that differences between adult and young dyslexics are the result of ongoing brain development through childhood and adolescence ${ }^{13,14}$ and learning processes during childhood and adolesence. Further research should be done to evaluate this interesting possibility.

The lack of activation in the temporal cortex in dyslexics during the rhyming task explains their poorer performance expressed in reaction times. The results suggest that phonologic processes are disrupted and that these processes depend on the temporal cortex. Similar findings were reported previously. For instance, Georgiewa et al also found decreased temporal activity for phonologic tasks in dyslexic children. ${ }^{11}$ For adults, Shaywitz et al reported lower activity in the temporal cortex for dyslexic readers as well. ${ }^{10}$ Moreover, the PET study of Paulesu et al also showed a lack of activity in dyslexic adults during a rhyming task. ${ }^{26}$

The semantic category task in the study of Shaywitz et al showed decreased activity at the posterior parietotemporal junction (Wernicke's area) in dyslexic adults. ${ }^{10} \mathrm{No}$ significant differences in the vicinity of this junction between the dyslexic children and controls with respect to brain areas were found in our study. It must, however, be remarked that to observe more functional MRI responses near Wernicke's area, more specialized functional MRI paradigms should be applied. 9,28,29 The atypical activation lateralization pattern in the prefrontal cortex found in our study with children may be attributable either to abnormalities in semantic processing itself or interferences of atypically lateralized orthographic or visual feature processing. Because no imaging study has probed semantic processes in children, more studies on semantic processes are needed to clarify these points. 
In conclusion, this controlled study in a homogeneous group of dyslexic children aged 11 to 12 years strengthens the notion that reading component processes in dyslexic children are atypically lateralized in the prefrontal cortex and that phonologic processes evoked during reading tasks in dyslexic children are disrupted and may underlie the deficit in reading. In addition, it has been shown that in dyslexic children, different brain circuits are activated with respect to normal readers during orthographic reading tasks, which may be related to an enhanced level of visuospatial feature processing to compensate for disruptions in language processing during reading. Further research should be performed to evaluate whether the present findings can be generalized to other age groups and to girls and whether there is a development in the deficient processing in dyslexia.

\section{Acknowledgment}

Many thanks to J an Wilmink for help during the preparation of the manuscript.

\section{References}

1. World Health Organization: The Internati onal Classi fi cati on of Di seases: Classi fi cati on of Mental and Behavi oural Di sorders, vol 10. Geneva, WHO, 1993.

2. Temple E, Poldrack RA, Protopapas A, et al: Proc Natl Acad Sci U S A 2000;5,97:13907-13912.

3. Helland T, Asbjornsen A: Neuropsychol Dev Cogn Sect C Chi Id Neuropsychol 2000;6(1):37-48.

4. Health Council of the Netherlands. Committee Dyslexia. Dyslexia. Definition and Treatment. The Hague, Health Council of The Netherlands, 1995. Publication no. 1995/15.

5. Rack JP, Snowling MJ, Olsen RK: Reading Research Quarterly 1992;27:29-53.

6. Bradley L, Bryant PE : Nature 1983;301:419-421.

7. Fletcher J M, Shaywitz SE, Shankweiler DP, et al: J Educ Psychol 1994;86:1-23.

8. Habib M: Brain 2000;123:2373-2399.
9. Habib M, Demonet J - F : Dyslexia and related learning disorders: Recent advances from brain imaging studies, in Mazziotta et al (eds): Brain Mapping. Chapter 18. The disorders. San Diego, Academic Press, 2000.

10. Shaywitz SE, Shaywitz BA, Pugh KR, et al: Proc Natl Acad Sci U S A 1998;95:2636-2641.

11. Georgiewa P, Rzanny R, Hopf J-M, et al: Neuroreport 1999; 10:3459-3465.

12. Temple E, Poldrack RA, Salidis J, et al: Neuroreport 2001; 12:299-307.

13. Giedd J N, Castellanos FX, Rajapakse JC, et al: Sexual dimorphism of the developing human brain. Prog Neuropsychopharmacol Biol Psychi atry 1997;21:1185-1201.

14. De Bellis MD, Keshavan MS, Beers SR, et al: Cerebr Cortex 2001;11:552-557.

15. Pennington BF : J Chi ld Psychol Psychi atry 1990;31:193-201.

16. Spring SP, Deutsch G: Left Brain, Right Brain: Perspectives from Cogni ti ve Neurosci ence. New York, Freeman, 1998.

17. Caesar FB: Veiligleren lezen. Tilburg, The Netherlands, Zwijsen,

18. Oldfield RC: Neuropsychologi a 1971;9:97-113.

19. Brus BT, Voeten MJ M: Eén Mi nuut Test. Nijmegen, Berkhout, 1973.

20. Pugh KR, Shaywitz BA, Shaywitz SE, et al: Brain 1996;119:1221-1238.

21. Backes WH, Mess WH, Van Kranen-Mastenbroek V, Reulen JPH: Clin Neurophysi ol 2000;111:1738-1744.

22. Friston KJ, Holmes AP, Worsley, et al: Hum Brain Map 1995;2:189-210.

23. Friston KJ, Holmes AP, Price CJ, et al: Neuroimage 1999;10:385-396.

24. Talairach J, Tournoux P: Co-planar Stereotaxic Atlas of the Human Brain. Stuttgart, Georg Thieme Verlag, 1988.

25. Gazzaniga MS, Ivry RB, Mangun GR: Cogni ti ve Neurosci enceTheBi ology of theMind. New York, WW Norton \& Company, 1998.

26. Paulesu E, Frith U, Snowling M, et al. Brain 1996;119:143-157.

27. Brunswick N, McCrory E, Price CJ , et al. Brain 1999;122:1901-1917.

28. Price C, Wise RJ S, Watson J DG, et al. Brain 1994;117:1255-1269.

29. Price C, Wise RJ S, Frackowiak RS. Cerebr Cortex 1996;61:62-70. 
Copyright $\odot 2003$ EBSCO Publishing 